\title{
Factors associated with pregnancy-associated glycoprotein (PAG) levels in plasma and milk of Holstein cows during early pregnancy and their effect on the accuracy of pregnancy diagnosis
}

\author{
A. Ricci, ${ }^{\star} \dagger$ P. D. Carvalho, ${ }^{*}$ M. C. Amundson, ${ }^{*}$ R. H. Fourdraine, $\ddagger$ L. Vincenti, $\dagger$ and P. M. Fricke ${ }^{* 1}$ \\ *Department of Dairy Science, University of Wisconsin-Madison, Madison 53706 \\ †Department of Veterinary Science, Università di Torino, Grugliasco 10090, Italy \\ $\ddagger$ AgSource Laboratories, Menomonie, WI 54751
}

\begin{abstract}
Lactating Holstein cows $(\mathrm{n}=141)$ were synchronized to receive their first timed artificial insemination (TAI). Blood and milk samples were collected 25 and $32 \mathrm{~d}$ after TAI, and pregnancy status was determined $32 \mathrm{~d}$ after TAI using transrectal ultrasonography. Cows diagnosed pregnant with singletons $(n=48)$ continued the experiment in which blood and milk samples were collected and pregnancy status was assessed weekly using transrectal ultrasonography from 39 to $102 \mathrm{~d}$ after TAI. Plasma and milk samples were assayed for pregnancy-associated glycoprotein (PAG) levels using commercial ELISA kits. Compared to ultrasonography, accuracy was $92 \%$ for the plasma PAG ELISA test and $89 \%$ for the milk PAG ELISA test $32 \mathrm{~d}$ after TAI. Plasma and milk PAG levels for pregnant cows increased from $25 \mathrm{~d}$ to an early peak $32 \mathrm{~d}$ after TAI. Plasma and milk PAG levels then decreased from $32 \mathrm{~d}$ after TAI to a nadir from 53 to $60 \mathrm{~d}$ after TAI for the plasma PAG assay and from 46 to $67 \mathrm{~d}$ after TAI for the milk PAG assay followed by an increase from 74 to $102 \mathrm{~d}$ after TAI. Overall, plasma PAG levels were approximately 2-fold greater compared with milk PAG levels, and primiparous cows had greater PAG levels in plasma and milk compared with multiparous cows. The incidence of pregnancy loss from 32 to $102 \mathrm{~d}$ after TAI based on ultrasonography was $13 \%$ for cows diagnosed with singleton pregnancies, and plasma and milk PAG levels decreased to nonpregnant levels within 7 to $14 \mathrm{~d}$ after pregnancy loss. Both plasma and milk PAG levels were negatively correlated with milk production for both primiparous and multiparous cows. We conclude that stage of gestation, parity, pregnancy loss, and milk production were associated with plasma and milk PAG levels after TAI similarly. Based on plasma and milk PAG profiles, the optimal time to conduct a first preg-
\end{abstract}

Received October 13, 2014.

Accepted December 5, 2014.

${ }^{1}$ Corresponding author: pmfricke@wisc.edu nancy diagnosis is around $32 \mathrm{~d}$ after AI coinciding with an early peak in PAG levels. Because of the occurrence of pregnancy loss, all pregnant cows should be retested $74 \mathrm{~d}$ after AI or later when plasma and milk PAG levels in pregnant cows have rebounded from their nadir.

Key words: pregnancy diagnosis, pregnancy-associated glycoprotein, milk, plasma

\section{INTRODUCTION}

Identification of nonpregnant dairy cows early after AI improves reproductive efficiency and pregnancy rate by decreasing the interval between AI services, thereby increasing the AI service rate (Fricke, 2002). Thus, new technologies to identify nonpregnant dairy cows and heifers early after AI may play a key role in management strategies to improve reproductive efficiency and profitability on dairy farms. Chemical tests for early pregnancy diagnosis use qualitative or quantitative measures of reproductive hormones at specific stages after AI or detect conceptus-specific substances in maternal circulation as indirect indicators of the presence of a viable pregnancy. Assays for detecting pregnancyassociated glycoprotein (PAG) levels in maternal circulation originating from mononucleated and binucleated cells of the embryonic trophoblast have been developed and commercialized to determine pregnancy status in cattle (Sasser et al., 1986; Zoli et al., 1992; Green et al., 2000). Pregnancy-specific protein-B (PSPB) was the first pregnancy-specific marker identified in cattle (Butler et al., 1982) and was later found to have the same N-terminal amino acid sequence as bovine PAG-1 (Xie et al., 1991; Lynch et al., 1992). Subsequently, PSPB was reclassified as bovine PAG-1, and an ELISA was developed to detect PAG as a method for early pregnancy diagnosis in cattle (Green et al., 2005).

Pregnancy-associated glycoproteins belong to a large family of inactive aspartic proteinases expressed by the placenta of domestic ruminants including cows, ewes, and goats (Haugejorden et al., 2006). In cattle, the PAG gene family comprises at least 22 transcribed 
genes as well as some variants (Telugu et al., 2009). Mean PAG concentrations in cattle increase from 15 to $35 \mathrm{~d}$ in gestation; however, variation in plasma PAG levels among cows precludes PAG testing as a reliable indicator of pregnancy until about 26 to $30 \mathrm{~d}$ after AI (Zoli et al., 1992; Humblot, 2001). Assessment of pregnancy status through detection of placental PAG levels in maternal blood (Sasser et al., 1986; Zoli et al., 1992; Green et al., 2005) is now used to evaluate pregnancy status within the context of a reproductive management scheme on commercial dairies (Silva et al., 2007, 2009; Sinedino et al., 2014). A commercial test for detecting PAG levels in milk (The Idexx Milk Pregnancy Test, Idexx Laboratories, Westbrook, ME) has been developed and marketed to the dairy industry and is now being assessed in field trials (Leblanc, 2013). Few studies, however, have reported factors associated with PAG levels in blood and milk of dairy cows early in gestation and the effect these factors may have on the accuracy of pregnancy diagnosis.

The objectives of this experiment were to assess factors associated with PAG levels in plasma and milk during early gestation in Holstein cows and to determine the accuracy of pregnancy outcomes based on PAG levels in plasma and milk compared with pregnancy outcomes based on transrectal ultrasonography.

\section{MATERIALS AND METHODS}

All experimental procedures were approved by the Animal Care and Use Committee of the College of Agricultural and Life Sciences at the University of Wisconsin-Madison.

\section{Synchronization of Ovulation and Timed Al}

Cows were housed at the University of WisconsinMadison Dairy Cattle Research Center (Arlington, WI) in free-stall barns with feedline headlocks. Cows were fed a TMR ad libitum formulated to meet or exceed NRC requirements (NRC, 2001) for high-producing dairy cows.

Lactating Holstein cows $(\mathrm{n}=141 ; 41$ primiparous and 100 multiparous) from $53 \pm 3$ DIM were synchronized for first timed AI (TAI) using a Double-Ovsynch protocol (Souza et al., 2008). Briefly, cows received the first $\mathrm{GnRH}$ injection $(100 \mu \mathrm{g}$ of gonadorelin diacetate tetrahydrate; Cystorelin; Merial, Duluth, GA) of the Presynch portion of the Double-Ovsynch protocol at 53 \pm 3 DIM, followed by an injection of $\mathrm{PGF}_{2 \alpha}(25 \mathrm{mg}$ of dinoprost tromethamine; Lutalyse; Zoetis, New York, NY) $7 \mathrm{~d}$ later and a GnRH injection $72 \mathrm{~h}$ after $\mathrm{PGF}_{2 \alpha}$. Seven days later, cows received an Ovsynch-56 protocol $\left[\mathrm{GnRH}(\mathrm{G} 1)\right.$ at $70 \pm 3$ DIM, $\mathrm{PGF}_{2 \alpha} 7$ d later, GnRH
$56 \mathrm{~h}$ after $\mathrm{PGF}_{2 \alpha}$, and $\mathrm{AI} 16$ to $20 \mathrm{~h}$ later], and all cows received a TAI at $80 \pm 3$ DIM. Three experienced AI technicians performed all inseminations using sires with high genetic merit and proven fertility.

\section{Pregnancy Diagnosis}

Pregnancy diagnosis was initially performed $32 \mathrm{~d}$ after TAI for all cows using a portable scanner (Ibex Pro; E. I. Medical Imaging, Loveland, $\mathrm{CO}$ ) equipped with a 7.5-MHz linear-array transducer. A positive pregnancy diagnosis was based on visualization of a corpus luteum on the ovary ipsilateral to the fluid-filled uterine horn containing an embryo with a heartbeat. Pregnant cows diagnosed with singletons $(\mathrm{n}=48)$ based on transrectal ultrasonography $32 \mathrm{~d}$ after TAI continued the experiment in which pregnancy status was assessed weekly using transrectal ultrasonography from 39 to $102 \mathrm{~d}$ after TAI. Cows diagnosed pregnant based on the presence of an embryo with a heartbeat and then diagnosed not pregnant at the subsequent examination based on the presence of a dead embryo or the absence of an embryo in the previously gravid uterine horn were considered to have undergone pregnancy loss.

\section{Blood and Milk Sampling}

Blood and milk samples were collected weekly from 25 to 102 d after TAI. From 32 to 102 d after TAI, blood and milk samples were collected from cows on the same day that pregnancy status was assessed using transrectal ultrasonography once a week. Blood samples were collected by venipuncture of the median coccygeal artery or vein into $10-\mathrm{mL}$ evacuated plasma collection tubes (Vacutainer; BD, Franklin Lakes, NJ) and immediately placed on ice. Blood samples were centrifuged $\left(1,600 \times g ; 4^{\circ} \mathrm{C}\right)$ for $20 \mathrm{~min}$, and plasma was harvested and stored at $-20^{\circ} \mathrm{C}$ in $2-\mathrm{mL}$ Safe-Lock Tubes (Eppendorf AG, Hamburg, Germany).

Composite milk samples $(35 \mathrm{~mL})$ were collected during the morning milking in the parlor. Milk samples were collected into $40-\mathrm{mL}$ polypropylene milk-collection vials containing $50 \mu \mathrm{L}$ of 2-bromo-2 nitropropane-1, 3-diol (18\% solution, Bronolab-W II, D\&F Control Systems Inc., Dublin, CA) as a preservative. Milk samples were immediately placed on ice and delivered to AgSource Laboratories (Verona, WI) within $2 \mathrm{~h}$ of collection.

\section{Plasma and Milk PAG ELISA}

After completion of sample collection at the end of the experiment, frozen plasma samples were shipped overnight in a cooled container by courier from the University of Wisconsin to Idexx Laboratories for analysis 
of plasma PAG levels using a commercial ELISA kit (the Idexx Bovine Pregnancy Test, Idexx Laboratories). Milk samples were delivered weekly to AgSource headquarters (Verona, WI) on the day of collection throughout the experiment and then to AgSource Laboratories (Menomonie, WI) for analysis of milk PAG levels using a commercial ELISA kit (The Idexx Milk Pregnancy Test, Idexx Laboratories).

Plasma and milk PAG ELISA tests were conducted according to the manufacturer's instructions by trained technicians who were blinded to the pregnancy status of the cows. Briefly, a microtiter plate format was configured by coating an anti-PAG monoclonal antibody onto the plate. The PAG monoclonal antibody was raised against the PAG-55 protein fraction comprising PAG-4, PAG-6, PAG-9, PAG-16, PAG-18, and PAG-19 (Nagappan et al., 2009). After incubation of the diluted test sample in the coated well, captured PAG was detected with a PAG-specific antibody (detector solution) and horseradish peroxidase conjugate. Unbound conjugate was washed away, and 3,3',5,5'-tetramethylbenzidine substrate was added to the wells. Color development was proportional to the amount of PAG in the sample and was measured using a spectrophotometer. Results were calculated from the optical density (OD) of the sample [corrected by subtraction of the reference wavelength $\mathrm{OD}$ of the sample $(\mathrm{S})$ minus the OD of the negative control $(\mathrm{N})$ at $450 \mathrm{~nm}$ (with both values corrected by subtraction of the reference wavelength OD of the negative control)], which resulted in an $\mathbf{S}-\mathbf{N}$ value. Each microplate included negative and positive controls.

Pregnancy outcomes were determined based on cutoff values determined by the PAG ELISA manufacturer. For the plasma PAG ELISA, when the S-N value was $<0.300$, the cow was classified "not pregnant"; when the S-N value was $>0.300$ to $<1.000$, the cow was classified "recheck"; and when the S-N value was $\geq 1.000$, the cow was classified "pregnant." For the milk PAG ELISA, when the $\mathrm{S}-\mathrm{N}$ value was $<0.100$, the cow was classified "not pregnant"; when the S-N value was $>0.100$ to $<0.250$, the cow was classified as "recheck"; and when the $\mathrm{S}-\mathrm{N}$ value was $\geq 0.250$, the cow was classified "pregnant."

\section{Milk Production}

Cows were milked twice daily at approximately 12-h intervals, and milk weights were recorded at each milking and stored in an on-farm dairy-management software program (DairyComp 305; Valley Agricultural Software, Tulare, CA). Milk weights from the 7-d period preceding the weekly milk and plasma sample collections were extracted from the software program and used to calculate weekly average milk production.

\section{Statistical Analyses}

Two cows had extremely high weekly milk PAG S-N values from 74 to $102 \mathrm{~d}$ after TAI. Based on an interquartile range analysis (PROC UNIVARIATE of SAS), data from these 2 cows were classified as outliers and were excluded from the analysis of milk PAG S-N profiles and from the analysis of the correlation between plasma and milk PAG S-N values. Pregnancy outcomes for these 2 cows were included in the analysis of milk PAG pregnancy outcomes.

Before statistical analysis for $\mathrm{S}-\mathrm{N}$ values for the plasma and milk PAG ELISA tests, normality of the data set was tested using the Shapiro-Wilk statistic and graphical methods obtained with PROC UNIVARIATE of SAS. Because nonnormality of the data was detected, data were transformed to ranks. After data transformation, differences in weekly plasma and milk S-N values from 25 to $102 \mathrm{~d}$ after TAI for pregnant cows were determined using ANOVA with repeated measures using PROC MIXED of SAS. The models contained the fixed effects of parity (primiparous vs. multiparous), time, and their interaction, whereas cow within parity was used as a random effect in the model. The correlation between plasma and milk PAG S-N values was analyzed using PROC CORR of SAS.

Pregnancy outcomes based on transrectal ultrasonography were considered the reference test (gold standard) to which outcomes from the plasma and milk PAG tests were compared by calculating the sensitivity, specificity, positive predictive value (PPV), negative predictive value (NPV), and accuracy. A total of 141 plasma samples were included in this analysis; however, because of missing milk samples $(n=6)$, a total of 135 milk samples were analyzed.

The sensitivity of the assays was expressed as the proportion of pregnant cows with a positive PAG ELISA test result [number of true-positive results/(number of true-positive results + number of false-negative results)]. Test specificity was calculated as the proportion of nonpregnant cows with a negative test result [number of true-negative results/(number of true-negative results + number of false-positive results)]. The PPV was calculated as the proportion of cows testing pregnant that were truly pregnant [number of true-positive results/(number of true-positive results + number of false-positive results)], and the NPV was calculated as the proportion of cows testing negative that were not truly pregnant [number of true-negative results/(number of true-negative results + number of false-negative 
results)]. Test accuracy was defined as the proportion of pregnant and nonpregnant cows correctly identified by the test [(number of true-positive results + number of true-negative results)/(number of true-positive results + number of true-negative results + number of false-positive results + number of false-negative results); Martin et al., 1987; Smith, 1991; Noordhuizen et al., 2001]. The rate of false-positive results is the likelihood of a positive result in cows known not to be pregnant, and this rate is related to the test specificity (rate of false positive $=1-$ specificity). The rate of false-negative results is the likelihood of a negative result in cows known to be pregnant, and this rate is related to the test sensitivity (rate of false-negative results $=1-$ sensitivity).

The kappa statistic in PROC FREQ of SAS was used to analyze agreement between reference pregnancy outcomes based on transrectal ultrasonography and the plasma and PAG ELISA pregnancy outcomes. A kappa value of 1 indicates perfect agreement and a value of 0 indicates no agreement beyond chance (Martin et al., 1987; Noordhuizen et al., 2001). In comparing tests, a kappa value of 0.4 to 0.5 indicates a moderate level of agreement, 0.5 to 0.6 indicates good agreement, and $>0.6$ indicates a high level of agreement (Martin et al., 1987). Based on a sample-size calculation (Watson and Petrie, 2010), a minimum of 123 cows are required to result in a kappa of 0.8 based on a confidence interval of 0.2 and an estimated true proportion of positives of 0.4 .

\section{RESULTS AND DISCUSSION}

\section{Synchronization and Pregnancy Outcomes}

Of the 141 cows enrolled in the Double Ovsynch protocol for first TAI, 3\% (4/141) failed to synchronize because of lack of complete luteal regression or lack of ovulation after the last GnRH injection, and these 4 cows were removed from all analyses. Overall, $42 \%$ (57/137) of synchronized cows were diagnosed pregnant $32 \mathrm{~d}$ after TAI. Two cows were diagnosed with twins based on ultrasonography $32 \mathrm{~d}$ after TAI, and these 2 cows were removed from all subsequent analyses. Overall, $87 \%(48 / 55)$ of pregnant cows maintained a singleton pregnancy from 32 to $102 \mathrm{~d}$ after TAI. Thus, the incidence of pregnancy loss from 32 to $102 \mathrm{~d}$ after TAI for cows diagnosed with singleton pregnancies was $13 \%(7 / 55)$.

\section{Plasma and Milk PAG Profiles}

To determine the weekly PAG profile in plasma and milk during the first trimester of gestation, data from cows that maintained a singleton pregnancy from 25 to $102 \mathrm{~d}$ after TAI $(\mathrm{n}=48)$ were analyzed (Figures 1 and 2). Overall, the weekly PAG profile in both plasma (Figure 1, upper panel) and milk (Figure 2, upper panel) from 25 to $102 \mathrm{~d}$ after TAI for pregnant cows was similar; however, plasma PAG levels were approximately 2-fold greater compared with milk PAG levels. Temporal PAG profiles from the present study are similar to other studies reporting PAG profiles in serum. In the first study to evaluate PSPB concentrations throughout gestation in Holstein cows (Sasser et al., 1986), serum PSPB (i.e., PAG-1) concentrations were detectable in some but not all cows $15 \mathrm{~d}$ after AI, increased to about $40 \mathrm{~d}$ after $\mathrm{AI}$ and stayed constant until about $70 \mathrm{~d}$, and then steadily increased until the end of gestation. A study that evaluated the same commercial PAG ELISA test kits evaluated in the present experiment reported similar relative PAG profiles (S-N values) in both plasma and milk (Lawson et al., 2014).

In the present study, plasma PAG levels were affected by both week after TAI $(P<0.01)$ and parity $(P=$ $0.009)$, and milk PAG levels were affected by both week after TAI $(P<0.01)$ and parity $(P=0.05)$. When all cows that maintained pregnancy from 25 to $102 \mathrm{~d}$ after TAI were analyzed (Figures 1 and 2), plasma and milk PAG levels increased from $25 \mathrm{~d}$ after TAI to an early peak $32 \mathrm{~d}$ after TAI. Plasma and milk PAG levels then decreased from $32 \mathrm{~d}$ after TAI to a nadir from 53 to 60 $\mathrm{d}$ after TAI for the plasma PAG ELISA and from 46 to $67 \mathrm{~d}$ after TAI for the milk PAG ELISA, followed by a gradual increase in PAG levels from 74 to $102 \mathrm{~d}$ after TAI. Primiparous cows had greater plasma and milk PAG levels compared with multiparous cows (Figures 3 and 4). A similar relationship between parity and serum PAG levels in crossbred Bos indicus beef cattle has been reported (Lobago et al., 2009).

The biological function of PAG is unclear because PAG levels in circulation constitute inactive aspartic proteinases (Xie et al., 1991; Telugu et al., 2009). Furthermore, the biology underlying temporal PAG levels during early pregnancy is not clearly understood. The transient decrease in PAG levels in pregnant cows after the early peak in PAG levels $32 \mathrm{~d}$ after TAI is intriguing. It is possible that production and secretion of PAG is regulated by other hormones during early pregnancy. By contrast, the decrease in PAG levels may be related to hormonal or physical changes in the placenta during this stage of gestation. The PAG gene family comprises at least 22 transcribed genes as well as some variants (Telugu et al., 2009), whereas the monoclonal antibody used in the plasma and milk ELISA tests evaluated in the present study recognizes only 6 of these PAG variants (Nagappan et al., 2009). 

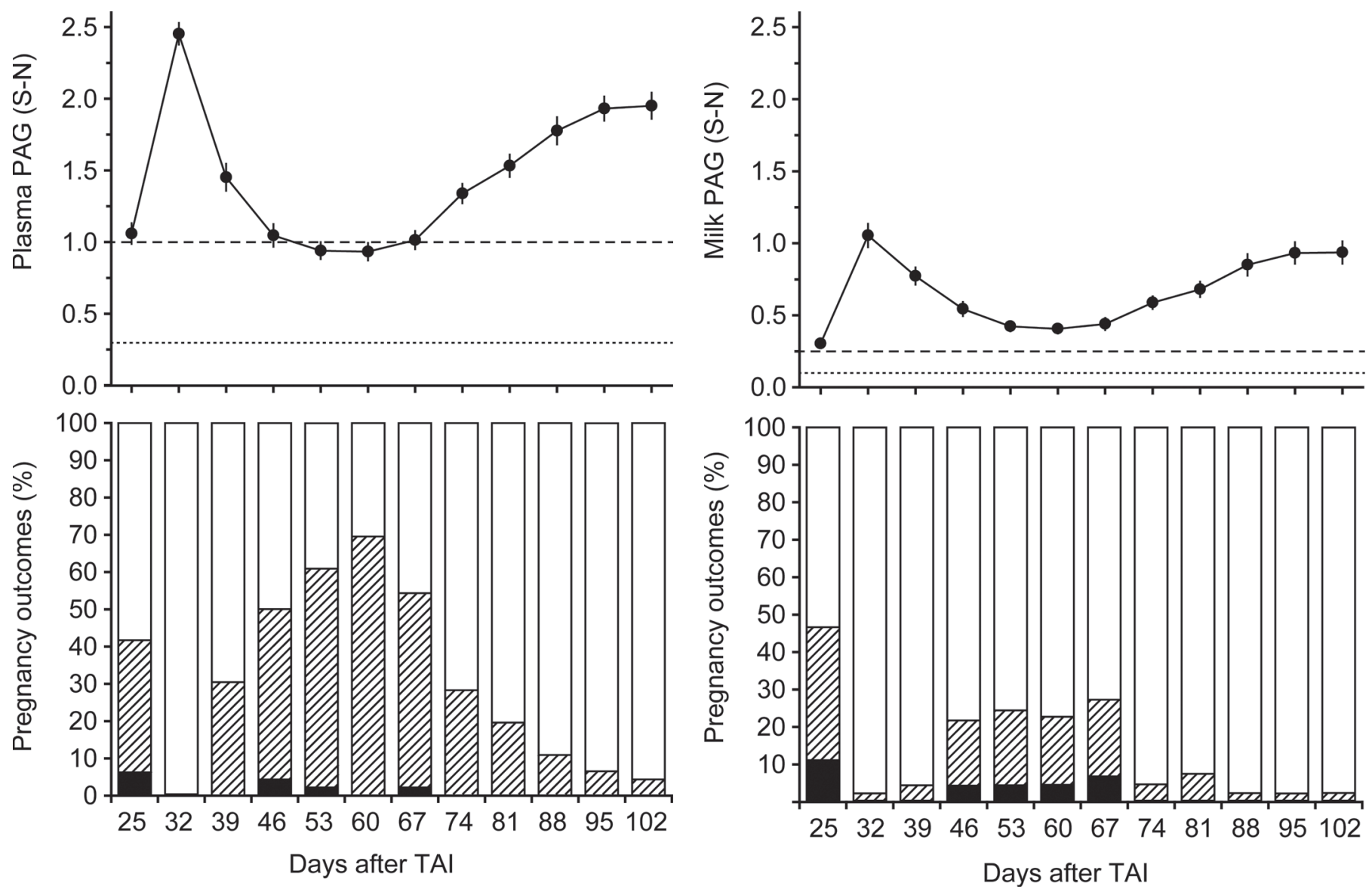

Figure 1. Plasma pregnancy-associated glycoprotein (PAG) profile for Holstein cows $(\mathrm{n}=48)$ that maintained pregnancy from 25 to 102 $\mathrm{d}$ after AI, and the resulting pregnancy-diagnosis outcomes of the plasma PAG ELISA test. (Upper panel) Plasma ELISA outcomes were calculated from the optical density (OD) of the sample [corrected by subtraction of the reference wavelength $\mathrm{OD}$ of the sample $(\mathrm{S})$ minus the OD of the negative control $(\mathrm{N})$ at $450 \mathrm{~nm}$ (with both values corrected by subtraction of the reference wavelength $\mathrm{OD}$ of the negative control)], which resulted in an S-N value. Mean ( \pm SEM) plasma PAG levels were affected by week after AI $(P<0.01)$. (Lower panel) When the $\mathrm{S}-\mathrm{N}$ value was $<0.300$ (dotted line in the upper panel), the cow was classified "not pregnant" (black bars); when the S-N value was $>0.300$ to $<1.000$, the cow was classified "recheck" (hatched bars); and when the $\mathrm{S}-\mathrm{N}$ value was $\geq 0.300$ (dashed line in the upper panel), the cow was classified "pregnant" (open bars). TAI = timed AI.

A correlation analysis was conducted to compare $\mathrm{S}-\mathrm{N}$ values from plasma and milk PAG ELISA tests within the same cows (Figure 5). Overall, S-N values between the plasma and milk PAG ELISA tests were highly correlated $\left(P<0.01 ; \mathrm{R}^{2}=0.64\right)$, and the slope of the regression line reflects the greater relative $\mathrm{PAG}$ concentrations in plasma compared with milk. These results agree with a similar analysis using the same commercial plasma and milk PAG ELISA tests that were evaluated in the present experiment (Lawson et al., 2014).

Figure 2. Milk pregnancy-associated glycoprotein (PAG) profile for pregnant Holstein cows $(\mathrm{n}=48)$ that maintained pregnancy from 25 to $102 \mathrm{~d}$ after AI, and the resulting pregnancy-diagnosis outcomes of the milk PAG ELISA test. (Upper panel) Milk ELISA outcomes were calculated from the optical density (OD) of the sample [corrected by subtraction of the reference wavelength OD of the sample (S) minus the OD of the negative control $(\mathrm{N})$ at $450 \mathrm{~nm}$ (with both values corrected by subtraction of the reference wavelength OD of the negative control)], which resulted in an S-N value. Mean $( \pm$ SEM) milk PAG levels were affected by week after AI $(P<0.01)$. (Lower panel) When the $\mathrm{S}-\mathrm{N}$ value was $<0.100$ (dotted line in the upper panel), the cow was classified "not pregnant" (black bars); when the S-N value was $>0.100$ to $<0.250$ (dashed line in the upper panel), the cow was classified as "recheck" (hatched bars); and when the S-N value was $\geq 0.250$, the cow was classified "pregnant" (open bars). TAI = timed AI.

\section{Accuracy of Plasma and Milk PAG ELISA Tests for Pregnant Cows}

To determine the accuracy of plasma and milk PAG ELISA outcomes during the first trimester of gestation, data from cows that maintained a singleton pregnancy from 25 to 102 d after TAI $(\mathrm{n}=48)$ were analyzed. Cows diagnosed pregnant $32 \mathrm{~d}$ after TAI based on transrectal ultrasonography continued the experiment in which pregnancy outcomes based on PAG levels in plasma and milk were classified based on cutoff lev- 

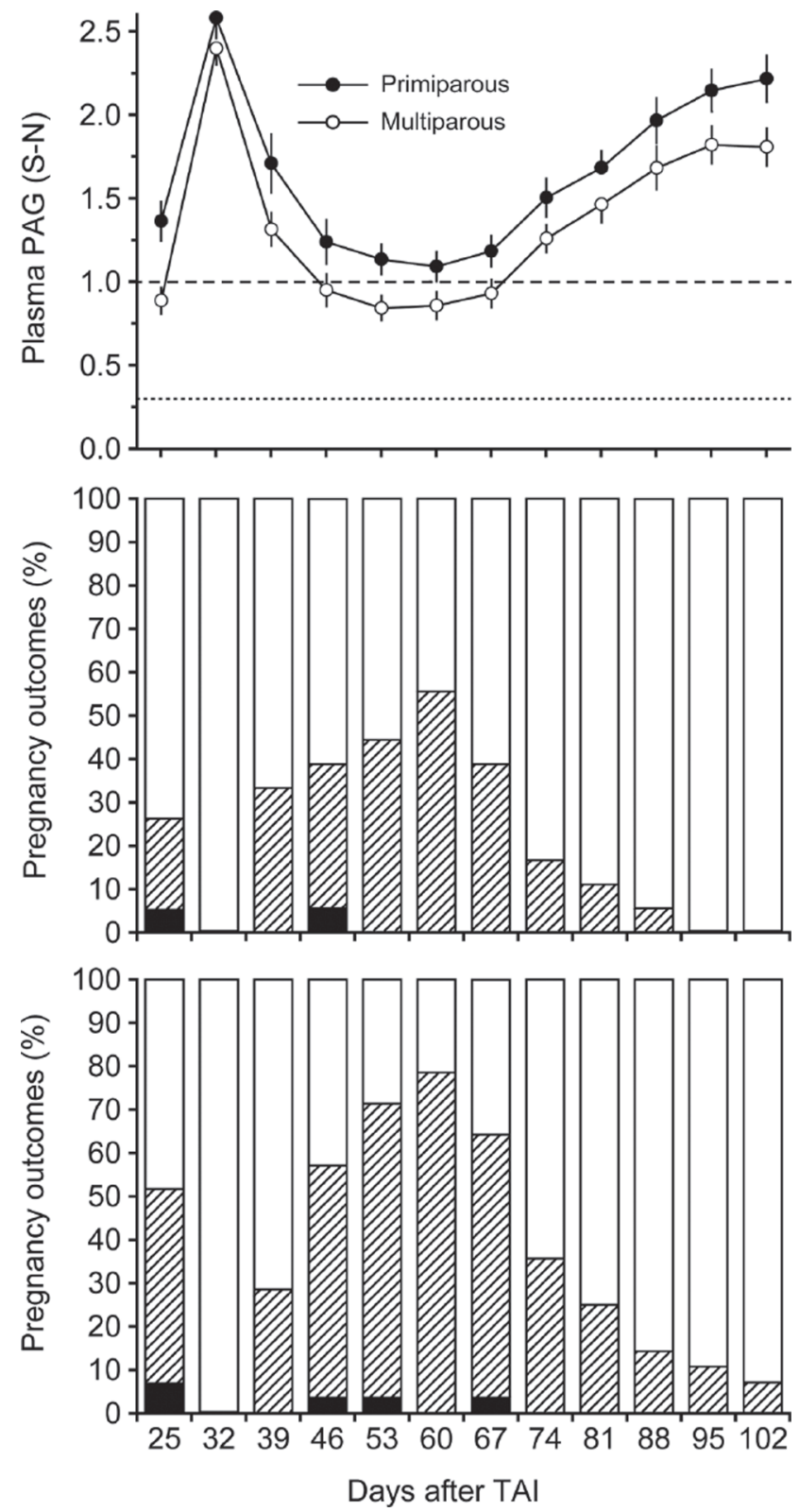

Figure 3. Association between plasma pregnancy-associated glycoprotein (PAG) profiles and parity for pregnant Holstein cows, and the resulting pregnancy-diagnosis outcomes of the plasma PAG ELISA test by parity. (Upper panel) Plasma PAG levels for primiparous $(\mathrm{n}=$ 19) and multiparous $(n=29)$ cows that maintained pregnancy from 25 to 102 d after AI. Plasma PAG ELISA outcomes were calculated from the optical density (OD) of the sample [corrected by subtraction of the reference wavelength OD of the sample (S) minus the OD of the negative control $(\mathrm{N})$ at $450 \mathrm{~nm}$ (with both values corrected by subtraction of the reference wavelength $\mathrm{OD}$ of the negative control)], which resulted in an S-N value. Mean ( \pm SEM) plasma PAG levels were affected by week after AI $(P<0.01)$ and parity $(P=0.009)$. (Middle panel) Pregnancy outcomes based on plasma PAG levels of primiparous cows. (Lower panel) Pregnancy outcomes based on plasma PAG levels of multiparous cows. When the $\mathrm{S}-\mathrm{N}$ value was $<0.300$ (dotted line in the upper panel), the cow was classified "not pregnant" (black bars); when the S-N value was $>0.300$ to $<1.000$, the cow was classified "recheck" (hatched bars); and when the S-N value was $\geq 0.300$ (dashed line in the upper panel), the cow was classified "pregnant" (open bars). TAI $=$ timed AI. els specified by the manufacturer. Overall, pregnancy outcomes for all pregnant cows based on both plasma and milk PAG ELISA tests were a reflection of PAG levels in plasma and milk (Figures 1 and 2). Although transrectal ultrasonography was not performed $25 \mathrm{~d}$ after TAI, we assumed that all cows pregnant $32 \mathrm{~d}$ after TAI based on ultrasonography were pregnant $25 \mathrm{~d}$ after TAI. Plasma and milk PAG ELISA outcomes of "not pregnant" and "recheck" occurred $25 \mathrm{~d}$ after TAI for pregnant cows. Plasma PAG ELISA outcomes for pregnant cows, however, were $100 \%$ pregnant $32 \mathrm{~d}$ after TAI, whereas the milk PAG ELISA exceeded $98 \%$ pregnant outcomes 32 and $39 \mathrm{~d}$ after TAI. Plasma and milk PAG ELISA outcomes of "not pregnant" and "recheck" increased concomitant to the temporal decrease in plasma and milk PAG levels during the nadir and then decreased as plasma and milk PAG levels increased as gestation ensued.

There also was a relationship between parity (primiparous vs. multiparous cows) and PAG levels in which the plasma and milk PAG ELISA tests generated fewer "not pregnant" and "recheck" outcomes for pregnant primiparous cows compared with pregnant multiparous cows (Figures 3 and 4). Thus, pregnancy outcomes across all days evaluated were more accurate for pregnant primiparous than for pregnant multiparous cows for both the plasma and the milk PAG ELISA tests.

In a study to assess aggressive early nonpregnancy diagnosis with a strategy for resynchronization of ovulation, pregnancy status of cows initiating the first GnRH injection of an Ovsynch protocol $25 \mathrm{~d}$ after TAI was determined $27 \mathrm{~d}$ after TAI by using a PAG ELISA test (Silva et al., 2009). Cows diagnosed not pregnant continued the Resynch protocol by receiving an injection of $\mathrm{PGF}_{2 \alpha} 7 \mathrm{~d}$ after the initial $\mathrm{GnRH}$ injection and a second $\mathrm{GnRH}$ injection $54 \mathrm{~h}$ after the $\mathrm{PGF}_{2 \alpha}$ injection. Cows received TAI approximately $16 \mathrm{~h}$ after the second GnRH injection $35 \mathrm{~d}$ after AI. The authors concluded that earlier detection of nonpregnant cows using the PAG ELISA in conjunction with a protocol for resynchronization of ovulation and TAI increased the rate at which cows became pregnant in a dairy herd compared with transrectal ultrasonography conducted at a later stage after TAI. This agrees with an economic simulation of use of chemical tests for identification of nonpregnant cows early after AI in conjunction with a protocol for resynchronization of ovulation and TAI, which concluded that the major economic advantage of using a chemical test was to decrease the interbreeding interval (Giordano et al., 2013). By contrast, another experiment similar in design to that of Silva et al. (2009) but with AI to estrus included throughout the experiment in addition to TAI showed no economic benefit of the early pregnancy test (Sinedino et al., 2014). This 

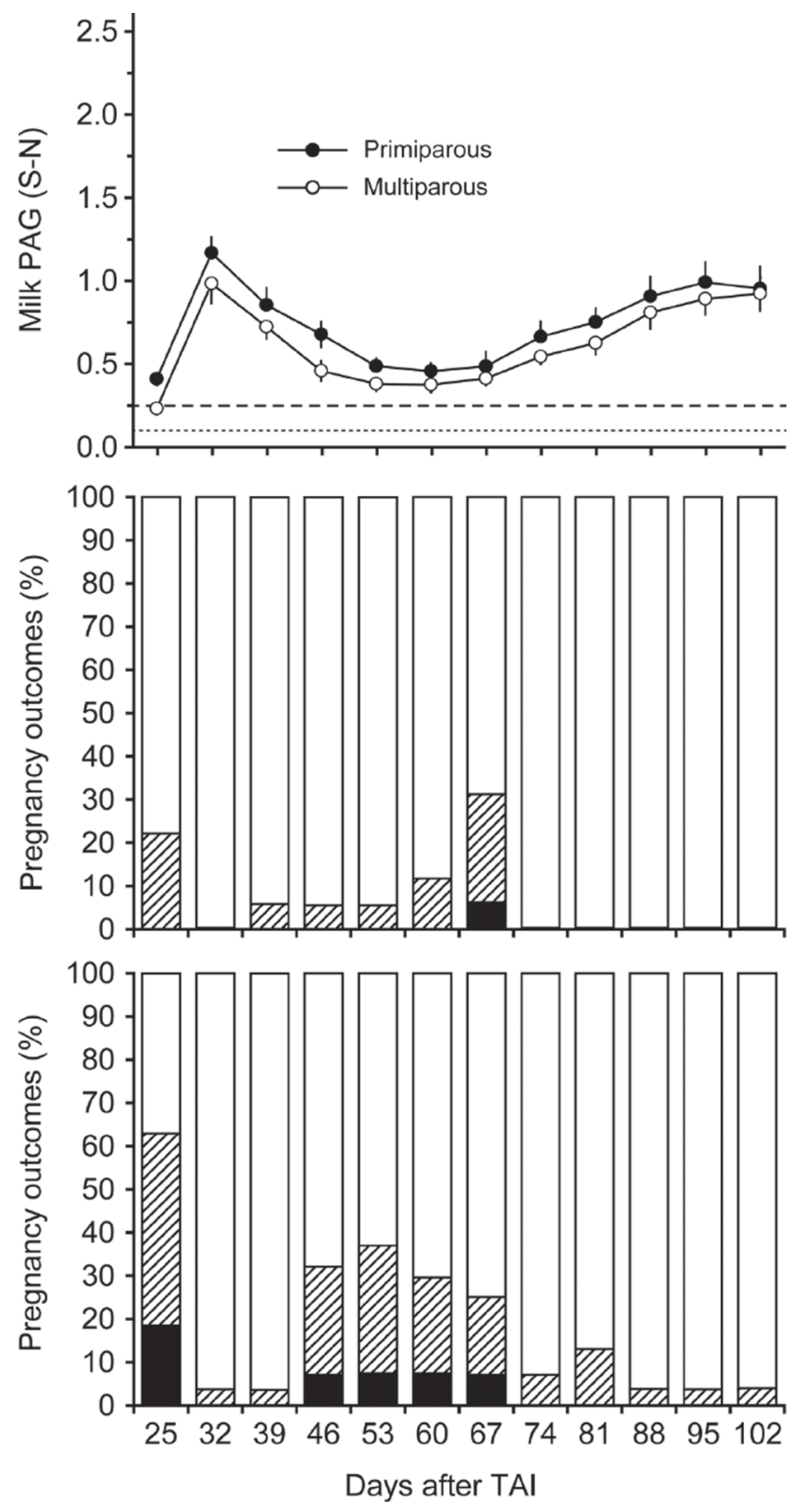

Figure 4. Association between milk pregnancy-associated glycoprotein (PAG) profiles and parity for pregnant Holstein cows, and the resulting pregnancy-diagnosis outcomes of the milk PAG ELISA test by parity. (Upper panel) Milk PAG profiles for primiparous $(\mathrm{n}=19)$ and multiparous $(\mathrm{n}=29)$ cows that maintained pregnancy from 25 to $102 \mathrm{~d}$ after AI. Milk ELISA outcomes were calculated from the optical density (OD) of the sample [corrected by subtraction of the reference wavelength $\mathrm{OD}$ of the sample $(\mathrm{S})$ minus the $\mathrm{OD}$ of the negative control $(\mathrm{N})$ at $450 \mathrm{~nm}$ (with both values corrected by subtraction of the reference wavelength OD of the negative control)], which resulted in an $\mathrm{S}-\mathrm{N}$ value. Mean $( \pm \mathrm{SEM})$ milk PAG levels were affected by week after AI $(P<0.01)$ and parity $(P=0.05)$. (Middle panel) Pregnancy outcomes based on milk PAG levels of primiparous cows. (Lower panel) Pregnancy outcomes based on milk PAG levels of multiparous cows When the $\mathrm{S}-\mathrm{N}$ value was $<0.100$ (dotted line in the upper panel), the cow was classified "not pregnant" (black bars); when the S-N value was $>0.100$ to $<0.250$, the cow was classified as "recheck" (hatched bars); and when the $\mathrm{S}-\mathrm{N}$ value was $\geq 0.250$ (dashed line in the upper panel), the cow was classified "pregnant" (open bars). TAI = timed AI. likely occurred because inseminating nonpregnant cows that returned to estrus decreased the interbreeding interval more than the strategy of early nonpregnancy diagnosis alone.

\section{Analysis of Pregnancy Outcomes 32 d After TAI}

To evaluate pregnancy outcomes from the plasma and milk PAG ELISA tests in cows of unknown pregnancy status, $2 \times 2$ contingency tables (Tables 1 and 2 ) were constructed to calculate sensitivity, specificity, PPV, NPV, and accuracy of the pregnancy outcomes for the plasma and milk PAG ELISA tests $32 \mathrm{~d}$ after TAI, and these outcomes were compared with those based on transrectal ultrasonography $32 \mathrm{~d}$ after TAI (Table 3). Sensitivity of both the plasma and milk PAG ELISA tests in the present experiment was high (100 and 98\%, respectively), compared with specificity (87 and $83 \%$, respectively). As a result, the NPV for the plasma and milk PAG ELISA tests in the present experiment was high (100 and 99\%, respectively) compared with the PPV of both tests ( 84 and $79 \%$, respectively). The overall accuracy of the plasma and milk PAG ELISA tests $32 \mathrm{~d}$ after TAI was 92 and $89 \%$, respectively. Statistical agreement (kappa) based on pregnancy outcomes based on transrectal ultrasonography $32 \mathrm{~d}$ after TAI was 0.84 for the plasma PAG ELISA and was 0.77 for the milk PAG ELISA (Table 3).

Results from the sensitivity analysis in the present study support that the accuracy of using plasma or milk PAG levels as an indicator of pregnancy status in dairy cows $32 \mathrm{~d}$ after AI is high, and our results agree with others who have conducted similar analyses from 27 to $39 \mathrm{~d}$ in gestation when PAG levels in both plasma and milk are at early peak levels (Silva et al., 2007; Lawson et al., 2014; Sinedino et al., 2014). By contrast, one study evaluated the milk PAG ELISA test for use as a pregnancy reconfirmation after an initial pregnant diagnosis was made by a veterinarian based on transrectal palpation (LeBlanc, 2013). In that experiment, the 661 cows diagnosed pregnant had a mean $( \pm \mathrm{SD})$ stage of gestation of $140 \pm 49 \mathrm{~d}$ (range $=60$ to $230 \mathrm{~d}$ ), and among 22 cows diagnosed not pregnant, the mean interval from the last AI was $153 \pm 83 \mathrm{~d}$ (range $=61$ to $341 \mathrm{~d}$ ). It is likely that most cows in that experiment were well past the nadir in milk PAG levels observed in the present study from 53 to $67 \mathrm{~d}$ after AI (Figure 2) based on the high sensitivity $(99.2 \%)$ and specificity $(95.5 \%)$ reported (LeBlanc, 2013). Based on plasma and milk PAG profiles in the present study, outcomes of a sensitivity analysis conducted during the temporal nadir for either plasma or milk PAG levels would have decreased dramatically. We were unable to accurately estimate these values after $32 \mathrm{~d}$ because only cows di- 


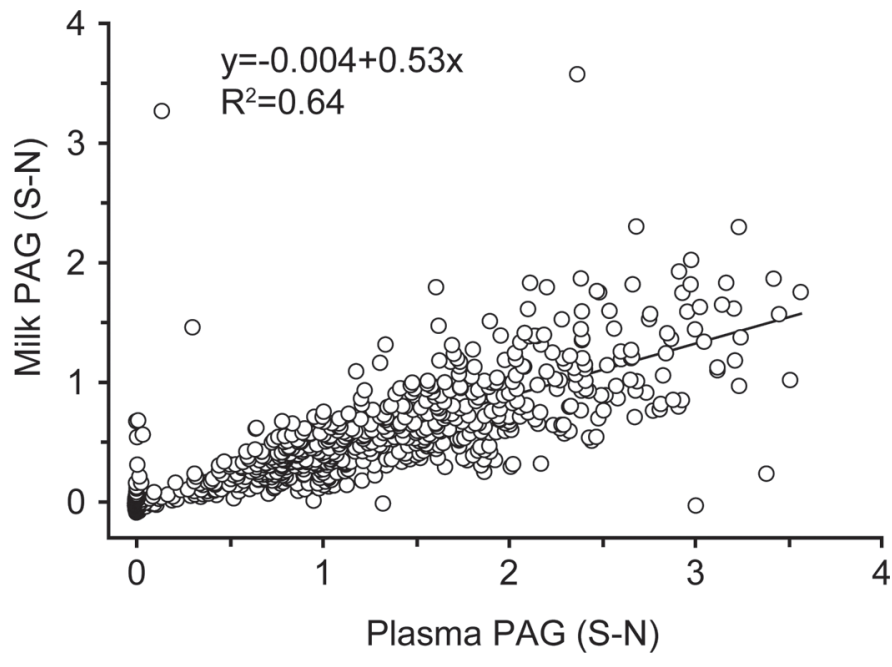

Figure 5. Relationship between relative levels of pregnancy-associated glycoproteins (PAG) in plasma and milk of Holstein cows from 25 to $102 \mathrm{~d}$ in gestation $\left(P<0.01 ; \mathrm{R}^{2}=0.64\right)$. Plasma and milk PAG ELISA outcomes were calculated from the optical density (OD) of the sample [corrected by subtraction of the reference wavelength OD of the sample (S) minus the OD of the negative control $(\mathrm{N})$ at $450 \mathrm{~nm}$ (with both values corrected by subtraction of the reference wavelength OD of the negative control)], which resulted in an $\mathrm{S}-\mathrm{N}$ value.

agnosed pregnant $32 \mathrm{~d}$ after TAI continued the experiment, thereby removing all nonpregnant cows, with the exception of the 7 cows that underwent pregnancy loss, from the calculations.

From an economic perspective, the sensitivity of an early nonpregnancy test (i.e., correct identification of pregnant cows) is more important than the specificity (i.e., correct identification of nonpregnant cows) based on 2 economic simulations (Ferguson and Galligan,

Table 1. Contingency table for evaluation of sensitivity, ${ }^{1}$ specificity ${ }^{2}$ positive predictive value, ${ }^{3}$ negative predictive value ${ }^{4}$ and accuracy ${ }^{5}$ of the plasma pregnancy-associated glycoprotein (PAG) ELISA test for determining pregnancy status $32 \mathrm{~d}$ after AI considering transrectal ultrasonography as the reference test

\begin{tabular}{lccc}
\hline & \multicolumn{2}{c}{ Transrectal ultrasound } & \\
\cline { 2 - 3 } PAG ELISA & Pregnant & Not pregnant & Total \\
\hline Pregnant & $57(a)$ & $11(b)$ & 68 \\
Not pregnant & $0(c)$ & $73(d)$ & 73 \\
Total & 57 & 84 & $141(N)$ \\
\hline
\end{tabular}

${ }^{1}$ Proportion of samples from pregnant cows with a positive PAG ELISA, $[a /(a+c)] \times 100$.

${ }^{2}$ Proportion of samples from not-pregnant cows with a negative PAG ELISA, $[d /(b+d)] \times 100$.

${ }^{3}$ Proportion of pregnant outcomes using the PAG ELISA that were truly pregnant, $[a /(a+b)] \times 100$.

${ }^{4}$ Proportion of not-pregnant outcomes using the PAG ELISA that were truly not pregnant, $[d /(c+d)] \times 100$.

${ }^{5}$ Proportion of pregnancy-status outcomes (pregnant and not pregnant) that were correctly classified using the PAG ELISA, $[(a+d) / N]$ $\times 100$.
Table 2. Contingency table for evaluation of sensitivity, ${ }^{1}$ specificity ${ }^{2}$ positive predictive value, ${ }^{3}$ negative predictive value, ${ }^{4}$ and accuracy $^{5}$ of the milk pregnancy-associated glycoprotein (PAG) ELISA test for determining pregnancy status $32 \mathrm{~d}$ after AI considering transrectal ultrasonography as the reference test

\begin{tabular}{lccc}
\hline & \multicolumn{2}{c}{ Transrectal ultrasound } & \\
\cline { 2 - 3 } PAG ELISA & Pregnant & Not pregnant & Total \\
\hline Pregnant & $52(a)$ & $14(b)$ & 66 \\
Not pregnant & $1(c)$ & $68(d)$ & 69 \\
Total & 53 & 82 & $135(N)$ \\
\hline
\end{tabular}

${ }^{1}$ Proportion of samples from pregnant cows with a positive PAG ELISA, $[a /(a+c)] \times 100$.

${ }^{2}$ Proportion of samples from not-pregnant cows with a negative PAG ELISA, $[d /(b+d)] \times 100$.

${ }^{3}$ Proportion of pregnant outcomes using the PAG ELISA that were truly pregnant, $[a /(a+b)] \times 100$.

${ }^{4}$ Proportion of not-pregnant outcomes using the PAG ELISA that were truly not pregnant, $[d /(c+d)] \times 100$.

${ }^{5}$ Proportion of pregnancy-status outcomes (pregnant and not pregnant) that were correctly classified using the PAG ELISA, $[(a+d) / N]$ $\times 100$.

2011; Giordano et al., 2013). Furthermore, to obtain a positive economic value for an early chemical nonpregnancy test, the sensitivity had to be greater than $96 \%$ when the test is used $31 \mathrm{~d}$ and greater than $94 \%$ when used $24 \mathrm{~d}$ after AI (Giordano et al., 2013). The sensitivity of both the plasma and the milk PAG ELISA tests evaluated in the present study (Table 3) as well as the sensitivity reported by others (Silva et al., 2007; Romano and Larson, 2010) exceed those criteria and support that use of these commercial tests to diagnose pregnancy status $32 \mathrm{~d}$ after AI would economically benefit a dairy farm.

Results from the present study support use of plasma PAG testing around $32 \mathrm{~d}$ after TAI and milk PAG testing 32 to $39 \mathrm{~d}$ after TAI when PAG levels in pregnant cows are at an early peak and pregnancy outcomes for pregnant cows approach $100 \%$ accuracy. Because we collected samples weekly, it was not possible to determine the earliest day between 25 and $32 \mathrm{~d}$ after TAI that is optimal for accurate pregnancy outcomes. By contrast, the advantages of the plasma and milk PAG ELISA tests are diminished when conducted during the temporal nadir in plasma and milk PAG levels from 46 to $74 \mathrm{~d}$ after TAI because of an increase in pregnant cows with outcomes of not pregnant or recheck (Figures $1,2,3$, and 4). Pregnant cows incorrectly diagnosed not pregnant ultimately may undergo iatrogenic pregnancy loss if they continue the resynchronization protocol and are treated with $\mathrm{PGF}_{2 \alpha}$, thereby resulting in an economic loss (Galligan et al., 2009; Giordano et al., 2013). The benefit of early pregnancy diagnosis is not to identify pregnant cows but rather to identify nonpregnant cows and rapidly return them to an AI service. Preg- 
Table 3. Sensitivity, ${ }^{1}$ specificity, ${ }^{2}$ positive predictive value $(\mathrm{PPV}),{ }^{3}$ negative predictive value $(\mathrm{NPV}),{ }^{4}$ and accuracy $^{5}$ of plasma and milk pregnancy-associated glycoprotein (PAG) ELISA tests for determination of pregnancy status $32 \mathrm{~d}$ after AI

\begin{tabular}{lrrrrrr}
\hline $\begin{array}{l}\text { PAG } \\
\text { ELISA }\end{array}$ & $\begin{array}{c}\text { Sensitivity } \\
{[\%(\text { no. } / \text { no. })]}\end{array}$ & $\begin{array}{c}\text { Specificity } \\
{[\%(\text { no. } / \text { no. })]}\end{array}$ & $\begin{array}{c}\text { PPV } \\
{[\%(\text { no. } / \text { no. })]}\end{array}$ & $\begin{array}{c}\text { NPV } \\
{[\%(\text { no. } / \text { no. })]}\end{array}$ & $\begin{array}{c}\text { Accuracy } \\
{[\%(\text { no. } / \text { no. })]}\end{array}$ & Kappa \\
\hline Plasma & $100(57 / 57)$ & $87(73 / 84)$ & $84(57 / 68)$ & $100(73 / 73)$ & $92(130 / 141)$ & 0.84 \\
Milk & $98(52 / 53)$ & $83(68 / 82)$ & $79(52 / 66)$ & $99(68 / 69)$ & $89(120 / 135)$ & 0.77 \\
\hline
\end{tabular}

${ }^{1}$ Proportion of pregnant cows with a positive PAG outcome.

${ }^{2}$ Proportion of not-pregnant cows with a negative PAG outcome.

${ }^{3}$ Proportion of cows diagnosed pregnant using PAG that truly were pregnant.

${ }^{4}$ Proportion of cows diagnosed as not pregnant using PAG that truly were not pregnant.

${ }^{5}$ Proportion of pregnancy status, pregnant and not pregnant, that was correctly classified by PAG.

nancy recheck outcomes decrease the specificity of the test, leading to a lost opportunity to rapidly return that cow to $\mathrm{AI}$ (i.e., $\mathrm{PGF}_{2 \alpha}$ cannot be administered to continue the resynchronization protocol). Thus, instead of completing the resynchronization protocol and receiving TAI, cows with recheck outcomes will not be reinseminated until they are either detected in estrus or diagnosed not pregnant at a pregnancy reconfirmation.

\section{Pregnancy Loss}

It has long been recommended that pregnancy status should be determined in dairy cows as soon as possible after AI but without having the diagnosis confounded by subsequent pregnancy loss (Studer, 1969; Melrose, 1979). The incidence of pregnancy loss in the present study for cows diagnosed with singleton pregnancies 32 $\mathrm{d}$ after TAI during the experiment was $13 \%(7 / 55)$, which agrees with the $13 \%$ loss reported to occur from 27 to $31 \mathrm{~d}$ and 38 to $50 \mathrm{~d}$ of gestation based on transrectal ultrasonography in a summary of 14 studies (Santos et al., 2004). Plasma and milk PAG profiles for the 7 cows in which pregnancy loss occurred are shown in Figure 6. Pregnancy outcomes based on the plasma and milk PAG ELISA tests were compared with pregnancy outcomes based on transrectal ultrasonography for the 7 cows undergoing pregnancy loss during the experiment (Table 4). For the plasma PAG ELISA, all but one cow (cow 4) that underwent pregnancy loss tested positive, whereas all cows undergoing pregnancy loss tested positive at one or more time points for the milk PAG test. Similarly, 5 of 7 cows tested recheck based on the plasma PAG test before the loss occurred compared with 3 of 7 cows based on the milk PAG test. Mean plasma and milk PAG S-N values for cows with viable pregnancies $32 \mathrm{~d}$ after TAI were similar $(P=0.14$ for plasma and $P=0.10$ for milk) for cows that went on to maintain their pregnancy compared with cows that went on to undergo pregnancy loss $(2.46 \pm 0.08$ vs. 2.12 \pm 0.26 , respectively, for plasma and $1.06 \pm 0.08$ vs. $0.76 \pm 0.14$, respectively, for milk). These results are in contrast to a study that evaluated PAG levels during early gestation in dairy cows and reported that cows maintaining pregnancy had greater plasma PAG concentrations $30 \mathrm{~d}$ after AI than cows that subsequently underwent pregnancy loss (Thompson et al., 2010).

Pregnancy loss diminishes the benefit of early pregnancy diagnosis in 2 ways. First, because of the high rate of embryonic mortality that occurs around the time during gestation that most early pregnancy tests are performed (Santos et al., 2004), the magnitude of pregnancy loss detected is greater the earlier after AI that a positive diagnosis is made. Thus, the earlier that pregnancy is diagnosed after AI, the fewer the nonpregnant cows that are identified to which a management strategy can be implemented to reinseminate them. Second, cows diagnosed pregnant earlier after AI have a greater period of risk during which observable pregnancy loss can occur compared with cows initially diagnosed pregnant later. If left unidentified, cows diagnosed pregnant early after AI that subsequently loose that pregnancy reduce reproductive efficiency by extending the interval from calving to the conception that results in a full-term pregnancy.

Results in Table 4 support that PAG levels detected by these ELISA tests have a half-life in maternal circulation resulting in a 7 to $14 \mathrm{~d}$ delay in identification of cows undergoing pregnancy loss based on plasma or milk PAG levels compared with transrectal ultrasonography. Because PAG levels are high during late gestation, it takes up to $60 \mathrm{~d}$ for residual PAG to be cleared from maternal circulation after parturition in cows (Sasser et al., 1986; Zoli et al., 1992) and other ruminants (Haugejorden et al., 2006). Because of the PAG half-life in circulation, cows submitted for a pregnancy diagnosis before $60 \mathrm{~d}$ postpartum can test positive because of residual PAG levels from the previous pregnancy (Giordano et al., 2012), and the 

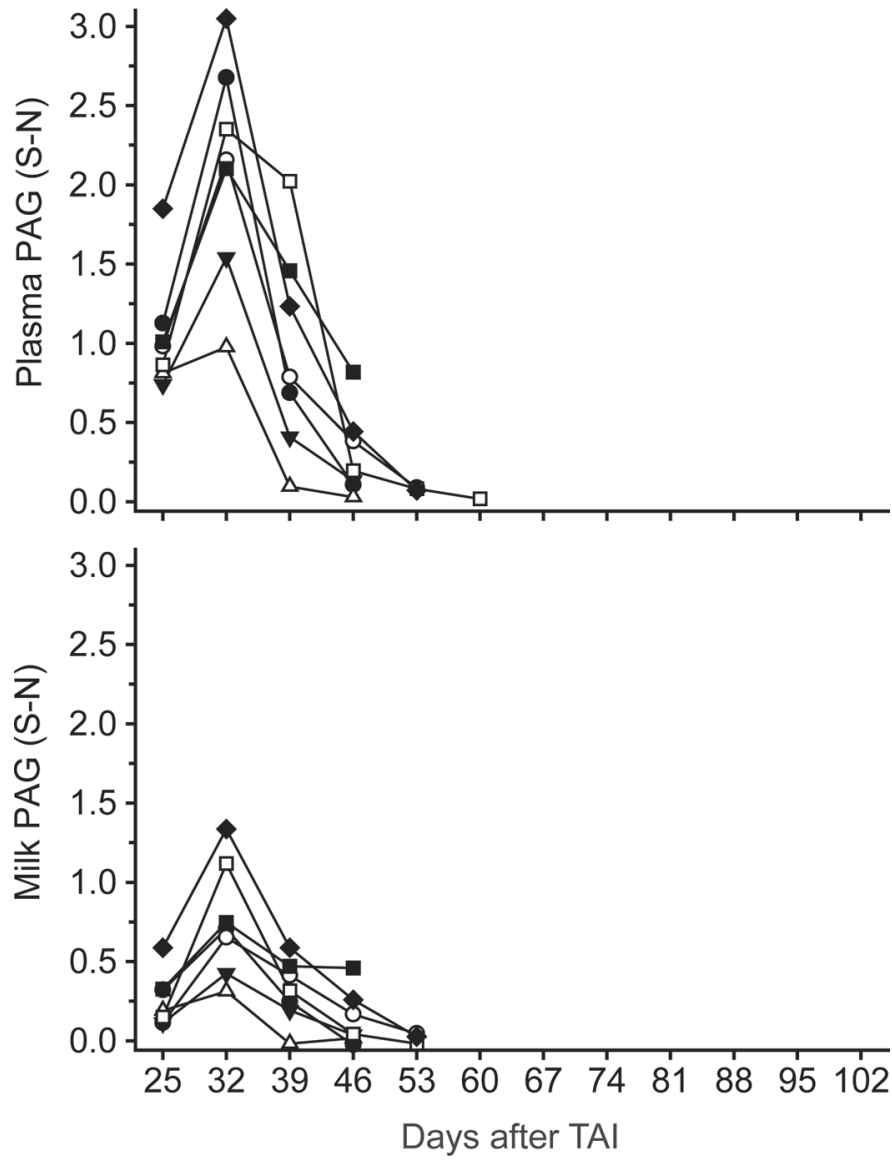

Figure 6. Profiles of pregnancy-associated glycoprotein (PAG) for individual Holstein cows $(\mathrm{n}=7)$ diagnosed pregnant using transrectal ultrasonography $32 \mathrm{~d}$ after AI and subsequently undergoing pregnancy loss. (Upper panel) Individual plasma PAG profiles. (Lower panel) Individual milk PAG profiles. Plasma and milk PAG ELISA outcomes were calculated from the optical density (OD) of the sample [corrected by subtraction of the reference wavelength OD of the sample (S) minus the $\mathrm{OD}$ of the negative control $(\mathrm{N})$ at $450 \mathrm{~nm}$ (with both values corrected by subtraction of the reference wavelength OD of the negative control)], which resulted in an S-N value. TAI = timed AI.

manufacturer of the plasma and milk PAG ELISA tests evaluated in this experiment recommends that cows be $>60 \mathrm{~d}$ after parturition when tested.

Based on serum samples assayed using the same PAG ELISA test evaluated in the present experiment to determine how rapidly PAG concentrations decrease after an induced pregnancy loss in dairy cows at 39 d in gestation (Giordano et al., 2012), approximately 5 to $7 \mathrm{~d}$ elapsed before PAG levels returned to basal levels when luteal regression was induced with $\mathrm{PGF}_{2 \alpha}$ or when the embryo died. Thus, most cows undergoing pregnancy loss will test pregnant or recheck at an early pregnancy diagnosis conducted using either the plasma or the milk PAG ELISA test. Because it is impossible to distinguish between the pregnancy outcomes of cows undergoing pregnancy loss (Figure 6 and Table 4) and those of pregnant cows that test as "recheck" or "not pregnant" during the temporal PAG nadir (Figures 1 and 2), it is important that all cows with "pregnant" or "recheck" outcomes at an early test be retested at a later time. Based on temporal PAG profiles in the present study, the best time to conduct a first pregnancy test is around $32 \mathrm{~d}$ after TAI, with all pregnant cows submitted for a pregnancy recheck $74 \mathrm{~d}$ after AI or later when PAG levels in plasma and milk of pregnant cows are rebounding from their nadir.

\section{Effect of Milk Production on Plasma and Milk PAG Levels}

Plasma PAG levels in pregnant cows were negatively correlated with milk production for both primiparous $\left(P=0.002 ; \mathrm{R}^{2}=0.05\right)$ and multiparous $\left(P<0.01 ; \mathrm{R}^{2}\right.$ $=0.18$ ) cows (Figure 7). Similarly, milk PAG levels in pregnant cows were negatively correlated with milk production for both primiparous $\left(P<0.01 ; \mathrm{R}^{2}=0.14\right)$ and multiparous $\left(P<0.01 ; \mathrm{R}^{2}=0.23\right)$ cows (Figure 8$)$. López-Gatius et al. (2007) first reported a negative association between plasma PAG levels and milk production in dairy cows. Because relative PAG concentrations decreased in both plasma and milk with increasing milk production, the negative association between PAG levels and milk production is not a result of dilution of PAG levels in milk with increasing production. One possible explanation not tested in this experiment is that PAG production by the conceptus decreases with increasing milk production. If PAG production by the conceptus is a proxy for embryonic growth and development during early pregnancy, the decrease in plasma and milk PAG levels with increasing milk production might suggest that cows with greater milk production may have had slower-growing embryos during early development. Cows with greater milk production may have lower progesterone concentrations early after timed AI because of increased hepatic metabolism of progesterone (Sangsritavong et al., 2002), which may inhibit growth of the embryo, leading to a decrease in PAG production. Because early embryos express progesterone receptors, the progesterone environment early after AI may play a role in embryo growth and development (Clemente et al., 2009). Several experiments using in vitro-fertilized embryos transferred into beef cows, however, support a direct role of circulating progesterone within the first 7 $\mathrm{d}$ after ovulation on the uterus that induces changes in the uterine environment that advance conceptus elongation (Carter et al., 2008, 2010; Larson et al., 2011). Further experiments are needed to fully understand the relationship between increased milk production and decreased PAG levels in plasma and milk and what, 
Table 4. Pregnancy outcomes for plasma and milk pregnancy-associated glycoprotein (PAG) ELISA tests compared with transrectal-ultrasonography pregnancy outcomes by day after AI for 7 Holstein cows that underwent pregnancy loss

\begin{tabular}{|c|c|c|c|c|}
\hline \multirow[b]{2}{*}{ Cow } & \multirow[b]{2}{*}{$\begin{array}{l}\text { Day after } \\
\text { timed AI }\end{array}$} & \multicolumn{3}{|c|}{ Pregnancy outcome ${ }^{1}$} \\
\hline & & Ultrasound & $\begin{array}{l}\text { Plasma PAG } \\
\text { ELISA }\end{array}$ & $\begin{array}{l}\text { Milk PAG } \\
\text { ELISA }\end{array}$ \\
\hline \multirow[t]{4}{*}{1} & 25 & - & + & + \\
\hline & 32 & $\mathrm{PG}$ & + & + \\
\hline & 39 & NP & $\mathrm{RE}$ & $\mathrm{RE}$ \\
\hline & 46 & NP & - & - \\
\hline \multirow[t]{5}{*}{2} & 25 & - & $\mathrm{RE}$ & $\mathrm{RE}$ \\
\hline & 32 & $\mathrm{PG}$ & + & + \\
\hline & 39 & $P G$ & $\mathrm{RE}$ & + \\
\hline & 46 & DF & $\mathrm{RE}$ & $\mathrm{RE}$ \\
\hline & 53 & NP & - & - \\
\hline \multirow[t]{4}{*}{3} & 25 & - & $\mathrm{RE}$ & $\mathrm{RE}$ \\
\hline & 32 & $P G$ & + & + \\
\hline & 39 & $P G$ & $\mathrm{RE}$ & $\mathrm{RE}$ \\
\hline & 46 & NP & - & - \\
\hline \multirow[t]{4}{*}{4} & 25 & - & $\mathrm{RE}$ & $\mathrm{RE}$ \\
\hline & 32 & $\mathrm{DF}$ & $\mathrm{RE}$ & + \\
\hline & 39 & $\mathrm{NP}$ & - & - \\
\hline & 46 & NP & - & - \\
\hline \multirow[t]{4}{*}{5} & 25 & - & + & + \\
\hline & 32 & PG & + & + \\
\hline & 39 & $\mathrm{PG}$ & + & + \\
\hline & 46 & NP & - & + \\
\hline \multirow[t]{5}{*}{6} & 25 & - & $\mathrm{RE}$ & $\mathrm{RE}$ \\
\hline & 32 & PG & + & + \\
\hline & 39 & $\mathrm{PG}$ & + & + \\
\hline & 46 & PG & - & - \\
\hline & 53 & NP & - & - \\
\hline \multirow[t]{5}{*}{7} & 25 & - & + & + \\
\hline & 32 & $\mathrm{PG}$ & + & + \\
\hline & 39 & PG & + & + \\
\hline & 46 & NP & $\mathrm{RE}$ & + \\
\hline & 53 & NP & - & - \\
\hline
\end{tabular}

${ }^{1}$ Pregnancy outcomes for ultrasound were based on the presence or absence of an embryo with or without a heartbeat and were classified as pregnant $(\mathrm{PG})$, embryo with a heartbeat; not pregnant $(\mathrm{NP})$, embryo not present; or dead fetus (DF), embryo without a heartbeat. Pregnancy outcomes for the plasma and milk PAG ELISA tests were classified as positive (+), negative (-), or recheck (RE) based on predetermined assay S-N cutoff values. S-N value = subtraction of the reference wavelength optical diameter (OD) of the sample (S) minus the $\mathrm{OD}$ of the negative control $(\mathrm{N})$ at $450 \mathrm{~nm}$ (with both values corrected by subtraction of the reference wavelength OD of the negative control).

if any, implications this may have on the health of the developing embryo.

\section{CONCLUSIONS}

This is one of the first studies to directly compare factors associated with plasma and milk PAG levels during the first trimester of gestation in Holstein cows. Stage of gestation, parity, pregnancy loss, and milk production were associated with relative PAG levels in both plasma and milk in a similar manner; however, milk PAG levels were about 2-fold lower than plasma PAG levels. Based on PAG profiles in plasma and milk samples collected weekly, the optimal time to conduct a first pregnancy diagnosis is around $32 \mathrm{~d}$ after TAI when plasma and milk PAG levels are at an early peak, whereas conducting either the plasma or milk PAG test during the temporal nadir in plasma and milk PAG levels would result in poor overall accuracy. Because of the occurrence of pregnancy loss, all pregnant cows should be submitted for a pregnancy recheck $74 \mathrm{~d}$ or later after AI when relative PAG levels in plasma and milk of pregnant cows have rebounded from their nadir.

\section{ACKNOWLEDGMENTS}

We thank AgSource Laboratories in Menomonie, Wisconsin, for running the milk PAG ELISA tests, and Idexx Laboratories in Westbrook, Maine, for running the plasma PAG ELISA tests. We also thank the farm personnel at the University of Wisconsin-Madison Emmons Blaine Dairy Cattle Research Center in 


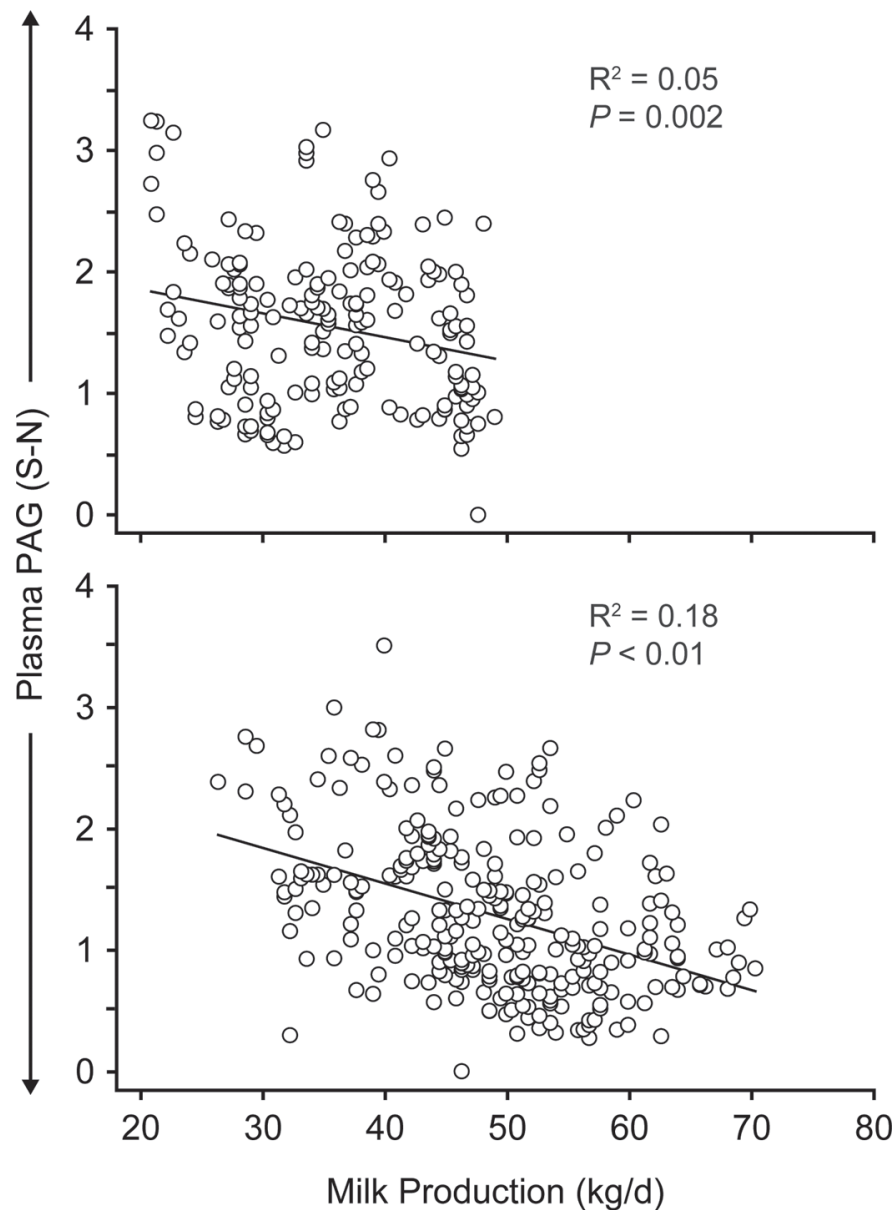

Figure 7. Relationship between milk production and relative levels of pregnancy-associated glycoprotein (PAG) in plasma of Holstein cows. Daily milk weights from the $7 \mathrm{~d}$ preceding the weekly plasmasample collection times were used to calculate weekly average milk production. Plasma PAG ELISA outcomes were calculated from the optical density (OD) of the sample [corrected by subtraction of the reference wavelength $\mathrm{OD}$ of the sample $(\mathrm{S})$ minus the OD of the negative control $(\mathrm{N})$ at $450 \mathrm{~nm}$ (with both values corrected by subtraction of the reference wavelength OD of the negative control)], which resulted in an $\mathrm{S}-\mathrm{N}$ value. (Upper panel) Primiparous cows. (Lower panel) Multiparous cows. Plasma PAG S-N values were negatively correlated with milk production for primiparous $\left(P=0.002 ; \mathrm{R}^{2}=0.05\right)$ and multiparous $\left(P<0.01 ; \mathrm{R}^{2}=0.18\right)$ cows.

Arlington, Wisconsin, for collecting the milk samples. This research was supported by Idexx Laboratories and Hatch project WIS01171 to P. M. F.

\section{REFERENCES}

Butler, J. E., W. C. Hamilton, R. G. Sasser, C. A. Ruder, G. M. Haas, and R. J. Williams. 1982. Detection and partial characterization of two bovine pregnancy-specific proteins. Biol. Reprod. 26:925-933. Carter, F., N. Forde, P. Duffy, M. Wade, T. Fair, M. A. Crowe, A. C. O. Evans, D. A. Kenny, J. F. Roche, and P. Lonergan. 2008. Effect of increasing progesterone concentration from day 3 of pregnancy on subsequent embryo survival and development in beef heifers. Reprod. Fertil. Dev. 20:368-375.

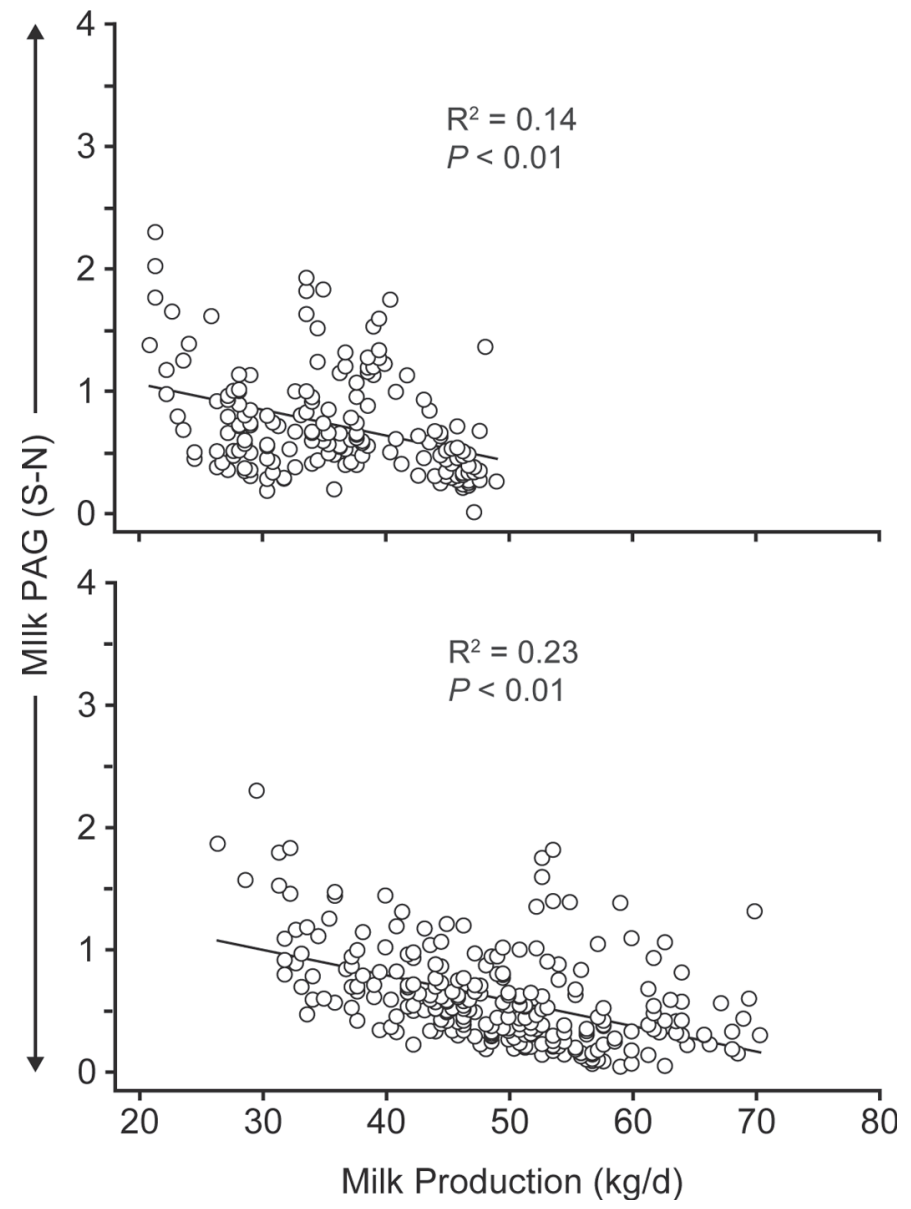

Figure 8. Relationship between milk production and relative levels of pregnancy-associated glycoprotein (PAG) in milk of Holstein cows. Daily milk weights from the $7 \mathrm{~d}$ preceding the weekly plasma-sample collection times were used to calculate weekly average milk production. Milk ELISA outcomes were calculated from the optical density (OD) of the sample [corrected by subtraction of the reference wavelength OD of the sample (S) minus the OD of the negative control (N) at $450 \mathrm{~nm}$ (with both values corrected by subtraction of the reference wavelength $\mathrm{OD}$ of the negative control)], which resulted in an S-N value. (Upper panel) Primiparous cows. (Lower panel) Multiparous cows. Milk PAG S-N values in pregnant cows were negatively correlated with milk production for primiparous $\left(P<0.01 ; \mathrm{R}^{2}=0.14\right)$ and multiparous $\left(P<0.01 ; \mathrm{R}^{2}=0.23\right)$ cows.

Carter, F., F. Rings, S. Mamo, M. Holker, A. Kuzmany, U. Besenfelder, V. Havlicek, J. P. Mehta, D. Tesfaye, K. Schellander, and P. Lonergan. 2010. Effect of elevated circulating progesterone concentration on bovine blastocyst development and global transcriptome following endoscopic transfer of in vitro produced embryos to the bovine oviduct. Biol. Reprod. 83:707-719.

Clemente, M., J. de la Fuente, T. Fair, A. Al Naib, A. Gutierrez-Adan, J. F. Roche, D. Rizos, and P. Lonergan. 2009. Progesterone and conceptus elongation in cattle: A direct effect on the embryo or an indirect effect via the endometrium? Reproduction 138:507-517.

Ferguson, J. D., and D. T. Galligan. 2011. The value of pregnancy diagnosis - A revisit to an old art. 2011 Theriogenology Annual Conference and Symposia, Milwaukee, WI. August 8-13, 2011.

Fricke, P. M. 2002. Scanning the future-Ultrasonography as a reproductive management tool for dairy cattle. J. Dairy Sci. 85:19181926. 
Galligan, D. T., J. Ferguson, R. Munson, D. Remsburg, and A. Skidmore. 2009. Economic concepts regarding early pregnancy testing. Pages 48-53 in Proc. Am. Assoc. Bovine Pract., Omaha, NE. Am. Assoc. Bovine Pract., Auburn, AL.

Giordano, J. O., P. M. Fricke, and V. E. Cabrera. 2013. Economics of resynchronization strategies including chemical tests to identify nonpregnant cows. J. Dairy Sci. 96:949-961.

Giordano, J. O., J. N. Guenther, G. Lopes Jr., and P. M. Fricke. 2012. Changes in plasma pregnancy-associated glycoprotein (PAG) pregnancy specific protein B (PSPB), and progesterone concentrations before and after induction of pregnancy loss in lactating dairy cows. J. Dairy Sci. 95:683-697.

Green, J. A., T. E. Parks, M. P. Avalle, B. P. Telugu, A. L. McLain, A. J. Peterson, W. McMillan, N. Mathialagan, R. R. Hook, S. Xie, and R. M. Roberts. 2005. The establishment of an ELISA for the detection of pregnancy-associated glycoproteins (PAGs) in the plasma of pregnant cows and heifers. Theriogenology 63:14811503.

Green, J. A., S. Xie, X. Quan, B. Bao, X. Gan, N. Mathialagan, J. F. Beckers, and R. M. Roberts. 2000. Pregnancy-associated bovine and ovine glycoproteins exhibit spatially and temporally distinct expression patterns during pregnancy. Biol. Reprod. 62:16241631.

Haugejorden, G., S. Waage, E. Dahl, K. Karlbert, J. F. Beckers, and E. Ropstad. 2006. Pregnancy associated glycoproteins (PAG) in postpartum cows, ewes, goats and their offspring. Theriogenology 66:1976-1984.

Humblot, P. 2001. Use of pregnancy specific proteins and progesterone assays to monitor pregnancy and determine the timing, frequencies and sources of embryonic mortality in ruminants. Theriogenology 56:1417-1433.

Larson, J. E., R. L. Krisher, and G. C. Lamb. 2011. Effects of supplemental progesterone on the development, metabolism and blastocyst cell number of bovine embryos produced in vitro. Reprod. Fertil. Dev. 23:311-318.

Lawson, B. C., A. H. Shahzad, K. A. Dolecheck, E. L. Martel, K. A. Velek, D. L. Ray, J. C. Lawrence, and W. J. Silva. 2014. A pregnancy detection assay using milk samples: Evaluation and considerations. J. Dairy Sci. 97:6316-6325.

LeBlanc, S. J. 2013. Short communication: Field evaluation of a pregnancy confirmation test using milk samples in dairy cows. J. Dairy Sci. 96:2345-2348.

Lobago, F., M. Bekana, H. Gustafsson, J. F. Beckers, G. Yohannes, Y. Aster, and H. Kindahl. 2009. Serum profiles of pregnancy-associated glycoprotein, oestrone sulphate and progesterone during gestation and some factors influencing the profiles in Ethiopian Borana and crossbred cattle. Reprod. Domest. Anim. 44:685-692.

López-Gatius, F., J. M. Garbayo, P. Santolaria, J. Yaniz, A. Ayad, N. M. de Sousa, and J. F. Beckers. 2007. Milk production correlates negatively with plasma levels of pregnancy-associated glycoprotein (PAG) during the early fetal period in high producing dairy cows with live fetuses. Domest. Anim. Endocrinol. 32:29-42.

Lynch, R. A., B. M. Alexander, and R. G. Sasser. 1992. The cloning and expression of the pregnancy-specific protein B. Biol. Reprod. 46(Suppl. 1):72.

Martin, S. W., A. H. Meek, and P. Willeberg. 1987. Measurement of disease frequency and production. Pages 62-76 in Veterinary Epidemiology: Principles and Methods. 1st ed. Iowa State Univ. Press, Ames.

Melrose, D. R. 1979. The need for, and possible methods of application of, hormone assay techniques for improving reproductive efficiency. Br. Vet. J. 135:453-459.

Nagappan, M., M. McGrath, and R. Schenkel. Inventors. 2009. Methods for early detection of pregnancy in cows. Monsanto Technology LLC, assignee. US Pat. No. 7,604,950 B2.
Noordhuizen, J. P. T. M., K. Frankena, M. V. Thrusfield, and E. A. M. Graat. 2001. Measurement of disease frequency. Pages 63 to 82 in Application of Quantitative Methods in Veterinary Epidemiology. 2nd ed. Wageningen Pers, Wageningen, the Netherlands.

NRC. 2001. Nutrient Requirements of Dairy Cattle. 7th ed. Natl. Acad. Sci., Washington, DC.

Romano, J. E., and J. E. Larson. 2010. Accuracy of pregnancy specific protein-B test for early pregnancy diagnosis in dairy cattle. Theriogenology 74:932-939.

Sangsritavong, S., D. K. Combs, R. Sartori, L. E. Armentano, and M. C. Wiltbank. 2002. High feed intake increases liver blood flow and metabolism of progesterone and estradiol- $17 \beta$ in dairy cattle. J. Dairy Sci. 85:2831-2842.

Santos, J. E. P., W. W. Thatcher, R. C. Chebel, R. L. A. Cerri, and K. N. Galvão. 2004. The effect of embryonic death rates in cattle on the efficacy of estrus synchronization programs. Anim. Reprod. Sci. 82-83:513-535.

Sasser, R. G., C. A. Ruder, K. A. Ivani, J. E. Butler, and W. C. Hamilton. 1986. Detection of pregnancy by radioimmunoassay of a novel pregnancy-specific protein in plasma of cows and a profile of plasma concentrations during gestation. Biol. Reprod. 35:936-942.

Silva, E., R. A. Sterry, D. Kolb, N. Mathialagan, M. F. McGrath J. M. Ballam, and P. M. Fricke. 2007. Accuracy of a pregnancyassociated glycoprotein ELISA to determine pregnancy status of lactating dairy cows twenty-seven days after timed artificial insemination. J. Dairy Sci. 90:4612-4622.

Silva, E., R. A. Sterry, D. Kolb, N. Mathialagan, M. F. McGrath, J. M. Ballam, and P. M. Fricke. 2009. Effect of interval to resynchronization of ovulation on fertility of lactating Holstein cows when using transrectal ultrasonography or a pregnancy-associated glycoprotein enzyme-linked immunosorbent assay to diagnose pregnancy status. J. Dairy Sci. 92:3643-3650.

Sinedino, L. D. P., F. S. Lima, R. S. Bisinotto, R. A. A. Cerri, and J. E. P. Santos. 2014. Effect of early or late resynchronization based on different methods of pregnancy diagnosis on reproductive performance of dairy cows. J. Dairy Sci. 97:4932-4941.

Smith, R. D. 1991. Evaluation of diagnostic tests. Pages 29 to 34 in Veterinary Clinical Epidemiology: A Problem-Oriented Approach. Butterworth-Heinemann, Stoneham, MA.

Souza, A. H., H. Ayres, R. M. Ferreira, and M. C. Wiltbank. 2008. A new presynchronization system (Double-Ovsynch) increases fertility at first postpartum timed AI in lactating dairy cows. Theriogenology 70:208-215.

Studer, E. 1969. Early pregnancy diagnosis and fetal death. Vet. Med. Small Anim. Clin. 64:613-617.

Telugu, B. P., A. M. Walker, and J. A. Green. 2009. Characterization of the bovine pregnancy-associated glycoprotein gene familyAnalysis of gene sequences, regulatory regions within the promoter and expression of selected genes. BMC Genomics 10:185-202.

Thompson, I. M., R. L. A. Cerri, I. H. Kim, J. A. Green, J. E. P. Santos, and W. W. Thatcher. 2010. Effects of resynchronization programs on pregnancy per artificial insemination, progesterone, and pregnancy-associated glycoproteins in plasma of lactating dairy cows. J. Dairy Sci. 93:4006-4018.

Watson, P. F., and A. Petrie. 2010. Method agreement analysis: A review of correct methodology. Theriogenology 73:1167-1179.

Xie, S., B. G. Low, K. K. Kramer, R. J. Nagel, R. V. Anthony, A. P. Zoli, J. F. Beckers, and R. M. Roberts. 1991. Identification of the major pregnancy-specific antigens of cattle and sheep as inactive members of the aspartic proteinase family. Proc. Natl. Acad. Sci. USA 88:10247-10251.

Zoli, A. P., L. A. Guilbault, P. Delahaut, W. B. Ortiz, and J. F. Beckers. 1992. Radioimmunoassay of a bovine pregnancy-associated glycoprotein in plasma: Its application for pregnancy diagnosis. Biol. Reprod. 46:83-92. 